\title{
Impact of COVID-19 on Student's Emotional and Financial Aspects in the Higher Learning Institutions
}

\author{
Muhammad Zarunnaim Haji Wahab ${ }^{* 1}$, Kamarudin Othman ${ }^{2}$ \\ Department of Banking, Faculty Business and Management, Universiti Teknologi Mara \\ Malaysia (UiTM), Kedah's branch. \\ Department of Economics, Faculty Business and Management, Universiti Teknologi \\ Mara Malaysia (UiTM), Kedah's branch
}

*Corresponding author: zarunnaim@yahoo.com

\begin{abstract}
Article History
Received 2021-04-07

Revised 2021-05-04

Revised 2021-05-09

Accepted 2021-05-14

Published 2021-06-01

\section{Keywords}

Impact of COVID-19, student's financial aspect,

student's emotional aspect,

students in higher learning institutions.
\end{abstract}

\section{How to cite?}

Wabab, M. Z. H., \& Otbman, $K$. (2021). Impact of COVID-19 on Student's Emotional and Financial Aspects in the Higher Learning Institutions. SEISENSE Journal of Management, 4(4), 1-15. doi: 10.33215/sjom.24i4.629

\section{Abstract}

Purpose- This paper aims to determine the impact of the COVID19 pandemic on the student's financial and emotional aspect at one of Malaysia's higher learning institutions (HLI).

Design/Methodology- The data collected from the online questionnaires involved 397 students and were analyzed using SPSS.

Findings- The findings showed a significant positive association between all variables where the strength range was from $r=.556$ to $\mathrm{r}=.565$. The highest correlation is the financial aspect ( $\mathrm{r}$-value .565) and is followed by the emotional aspect (.556). Next, the results also revealed that both variables were significantly influenced where the $\mathrm{R}^{2}$ value was $47.1 \%$ while other factors explained the additional $53 \%$ of the element.

Practical Implications- There are some significant implications identified in this study. First, this study's findings directly impacted the COVID-19 pandemic, especially in terms of financial support and the emotional aspect. Second, the result indicated that the university should also consider other internal and external aspects rather than focus only on improving the learning process. Third, this study would enrich the current body of knowledge about the impact of COVID-19. 


\section{Introduction}

The novel coronavirus is an unprecedented global war, where humanity is facing the same enemy. This pandemic is a common challenge that is faced by humankind in the age of globalization. Up to date, the world population is struggling to handle this COVID-19 outbreak, and on 12 $2^{\text {th }}$ March 2020, the World Health Organization (WHO) has confirmed COVID-19 as a pandemic that threatens human life (WHO, 2020). Up till the early of May 2021, more than 152 million cases of those infected by the virus were known, involving countries worldwide where the United States had recorded the highest number of cases, i.e., around 32 million with more than 577,000deaths (WHO, 2021). This virus was initially traced from Wuhan, China, on 31st. December 2019 (Reynolds, 2020), which up to date it had killed more than 3.2 million people around the world (WHO, 2021).

The invisible enemy that the people are facing today has also affected all the industries in the world, including the education sector. Due to the virus's spread, the global higher education landscape has shifted drastically in recent months (Aristovnik et al., 2020). Most of the students worldwide are affected when their schools and institutions have started to close the operations to curb the spread of this contagious pandemic. Many countries have made a drastic effort to mitigate the transmission of the COVID-19 among their population, i.e., by the widespread closure of primary and secondary schools, colleges, hospitals, universities, and other public facilities. Data from UNESCO (2020) shown that by the end of May 2020, about 150 countries have shut down educational institutions nationwide, which affects over $70 \%$ of the world's student population.

Based on the existing large body of literature, closing educational facilities is one of the most effective ways to sever vital transmission chains and reduce the dissemination of virus infection in the population (Kawano and Kakehashi, 2015; Wheeler et al., 2010). In terms of the increasing alarm regarding the spread of COVID-19 pandemic, many universities worldwide have decided, either canceled or delayed all campus gatherings, including face-to-face lectures, seminars, conventions, and intra and inter-university sports tournaments, and other activities. The university management has worked quickly to transform their courses and services from a conventional delivery style (face-to-face approach) to an online delivery learning. (Gewin, 2020; THE, 2020a). Online teaching is becoming a normalization approach and no longer a new method of delivery for most university students. The faculty staff is trained to adopt online learning systems as the sole mode of delivery teaching or as a supplement to face-to-face instruction (also known as a hybrid platform) (THE, 2020b, Nuryantini and Yudhiantara, 2019). Therefore, COVID-19 transmissions are confirmed will incur other effects (internally and externally) upon the parties involved, especially on the student. Thus, this study will focus on two potential impacts of the COVID-19 transmission in terms of education and mental health among university students, i.e., financial support and the emotional aspects.

This research is essential due to several factors. First, the COVID-19 pandemic is a new outbreak. Thus there is a minimal study on its impacts on the world population, especially from the students' perspectives. It is in line with the suggestion by Grubic et al. (2020) that states it is time for scholars to study the impact of COVID19 on students' mental health as well as the possible interventions that must be taken immediately. Second, the transmission mode of study from conventional approaches to online mode will impact the external factors (Aristovnik et al., 2020), such as the financial and emotional aspects. Third, many researchers in education biology have neglected to consider the importance of developing a suitable environment for the learning process (Crispim et al., 2021). Fourth, this study will also strengthen the current literature that is related to COVID-19, which up to date, is still very limited.

By the adopted theory of stress by Selye (1976) and the recent studies that link to the theory, this research aims to determine the level of interaction between financial and emotional stress factors towards the impacts of COVID-19 among students in higher learning institutions. Correspondingly, this research studies and has 
performed research on one of the public universities in Malaysia: Universiti Teknologi Mara Malaysia (UiTM), Kedah's branch. The organization of this paper is as follows: Section 1 contains a concise introduction, while Section 2 and Section 3 presents the literature studies and methodology of this research, respectively; Section 4 and Section 5 discuss the findings, conclusions, and the limitations of the study.

\section{Literature Review}

\section{Financial Support}

The student's financial support is an essential criterion in the education sector, especially at the higher learning institutions level. The cumulative amount of expenses for undergraduate and postgraduate education levels has increased from year to year (Faulk et al., 2010). Thus, previous literature has pointed out that, without proper planning, the student will face financial support problem, which later will lead to many other issues; such as academic problem, emotional and mental wellbeing, and also the desire to pursue work after graduation(Bodvarsson \& Walker, 2004; Lyons, 2003; Lyons, 2004; Nnamani et al., 2014).

Financial support is one of the crucial issues faced by most students even before the pandemic occurred. A study by Pew Research Center in 2019 found that 6 out of 10 parents with children aged 18 to 29 say they have provided financial assistance to their children in the previous year, mainly for regular costs such as tuition fee payments, rent, meals, as well as bills. This showed that the young generation nowadays was heavily dependent on their parents for financial support compared to 1980. A third of young people were financially self-sufficient by the age of 22 or much more youthful.

Thus, related to the current COVID-19 pandemic that is being faced, continuous financial support among students is one of the essential criteria that need to be addressed. According to WalletHub's in the " 2020 College Student Financial survey", more than a 13 million college students are anxious about their future finances. The report added that more than 6.4 million college students say they already receive credit card support from their parents, according to a survey among 300 students conducted in August 2020.

Financially, many students today are worrying about debts or student loans, application fees, rental housing fees, books, study materials (Gutiérrez, 2020), student job loss, concerns about their future financial status, future education as well as their career (Brooks et al., 2020; Statista, 2020; Elmer et al., 2020). Moreover, some of them have started to find other initiatives to support their studies by exploring freelancing opportunities, looking for jobs in high demand during this period, and many more.

All parties such as the universities, governments, banking/financial institutions, and student loan organizations need to work together to assist graduates in various ways, including immediate case assistance and temporary loan relief. Universities should consider the issues such as financial aid and general living costs for vulnerable students (Pradeep Sahu, 2020). This ensures that the problem in financial support among university students can be mitigated and managed correctly. Thus, based on the analysis of past literature, this study investigates the relationship between the financial support aspect and pandemic COVID-19 among students in higher learning institutions.

\section{Student's Emotional}

The COVID-19 transmission has brought many disruptions to all people across the world. The dramatic rise in infected cases has generated a sense of uncertainty and anxiety in public about what will happen in the future. As known, the current health crisis is expected to affect emotional and mental wellbeing. The feeling of insecurity and anxiety also caused tremendous tension among university residents, including students. This burden can negatively affect students' learning performance and mental health (Al-Rabiaahab et al., 2020; Kafka, 2020). In turn, this affected how students learn; anxiety complicates focusing and attention capacity. 
Hence, amid the COVID-19 crisis, students' mental wellbeing is a top priority, as they are confronted with unprecedented uncertainty. This is the critical concern of education institutions to mitigate this issue and ensure students' wellbeing and staff. Thus, establishing effective social relationships between students, lecturers, and university administration would help achieve that goal (OECD, 2020). However, other issues might arise, such as whether the universities are taking proactive steps to support students' emotions and mental wellbeing, whether universities have provided specially qualified counselors who can understand such students' problems and others (THE, 2020c).

On the other hand, Pintrich et al. (1993) stated that the learning processes aren't close to being classified as "cold cognition." Still, other additional factors like social variables should also be considered in developing an environment for a good learning process. According to psychological research, emotions are also essential in the learning process and performance in certain situations. However, currently, the emotional aspects have not been sufficiently addressed in the learning education system (Gläser-Zikuda et al., 2005; Rahmawati, Resma et al., 2019). Sometimes, they have been ignored in research relate to biology education. Notably, positive emotions were directly linked to positively influencing learning and achievement processes whereas negative emotions have brought the opposite effect (Laukenmann et al., 2003; Pekrun et al., 2002).

Based on the literature, this paper concludes that the emotional factor plays a significant role in creating a conducive learning process. Thus, one of the research questions was developed: the correlations between emotional variables and the impact of the COVID-19 among the students in public higher learning institutions (HLI).

\section{Impact on Student}

The coronavirus transmission has had a significant effect on students at all higher education levels, from internal and external factors such as travel bans to physical distancing, quarantine expenses, university closures, and changes in learning mode, financial support, and emotional aspects. Research by QS (2020) in mid-February related to the impact of the pandemic on global higher education revealed that $46 \%$ of the students agreed that COVID-19 affected their study plans, whereas $29 \%$ answered 'no' and 25\% was not sure about it.

The QS (2020) report also presents many international students' worries about travel bans, airline cancellations, difficulties with receiving scholarship interviews, passport applications, or language testing, exam cancellations or postponements, and health issues. Thus, $47 \%$ of them have intended to defer their study until the pandemic situation has recovered. Another $13 \%$ are willing to change their research to another country with lower cases of the virus, $8 \%$ decide to discontinue from studying overseas, and the rest that is $32 \%$, has made other decisions on this matter.

As is known, most universities worldwide currently have to dramatically switch their learning approach from face-to-face to Open Distance Learning (ODL), thus further inducing anxiety problems among the parties involved, especially the students. Studies on the COVID-19 impact on Chinese college students have observed significant negative effects on students' psychological wellbeing with high anxiety levels. For example, the research by Cao et al. (2020) related to the psychological effect on university students in China revealed that from the 7,143 students' responses, $0.9 \%$ had severe anxiety, whereas $2.7 \%$ and 21.3 had moderate anxiety and mild anxiety, respectively. Besides, another study by Wang et al. (2020) also found similar findings, from 1,210 students that had been investigated, who came from 194 cities in China, 53.8 percent of the respondents had severe to moderate psychological effect, with female students being those who were associated with more significant psychological impacts.

Based on the analysis, early research has shown that pandemics harm students' psychological wellbeing and have various consequences. Thus, it can be concluded that the COVID-19 pandemic has brought a significant 
impact on the students in many aspects, including their financial support and emotional aspect. Thus, this research aims to determine the relationship between the financial and emotional effects of the COVID-19 pandemic among students in Malaysian higher education institutions.

According to the previous literature, the framework for this study is developed as follows:

IVs:

DV:

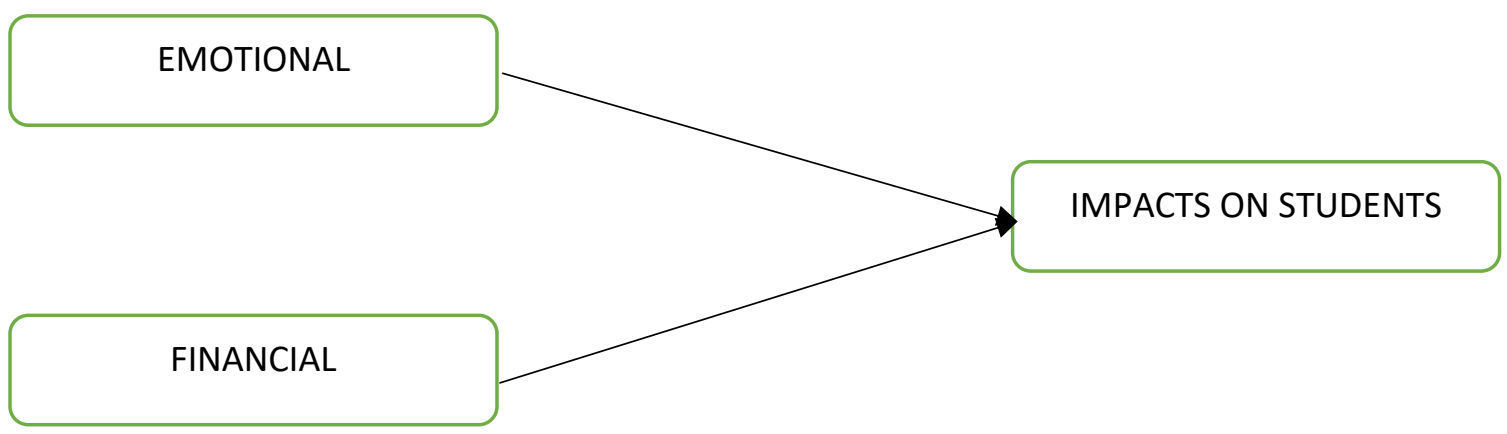

Figure 1. Framework of this study

Two hypotheses have been developed:

H1. There is a significant positive relationship between the emotional aspect, financial aspect, and the impact of COVID-19 among Malaysian students in bigher learning institutions.

H2. There is a significant favorable influence between the emotional, financial, and impact of COVID-19 among Malaysian students in higher learning institutions.

\section{Methodology}

\section{Research design}

This study has applied the quantitative method through an online survey approach. The formulation of the questions was built based on a credible source based on proven previous studies to ensure that the reliable and capable of answering the research objectives. However, some of the questions have been modified to suit the respondent's background and the current situation according to the feedback of the pilot test. The questionnaire was used a five-point Likert scale tool to interpret the data from the respondents. Thus, the variables and critical source of items in this analysis are shown in Table 1.

Table 1. The variables and the primary source of questionnaire items.

\begin{tabular}{ll}
\hline Variables & Authors \\
\hline Emotional & Gläser-Zikuda et al. (2005) \\
Financial & Edirisuriya (2015) \\
Impact on students & Irfan and Shabana (2012) \\
\hline
\end{tabular}

Source: self-constructed

\section{Population and sampling}

The target population of this study is derived from one of the public higher education institutions in Malaysia, Universiti Teknologi Mara Malaysia (UiTM), Kedah's branch. Generally, students at UiTM Kedah can be divided into four main categories based on their educational background: foundation, diploma, bachelor degree, and postgraduate students (excluded in this research). The total number of students from those three categories, 
7,264 , has been chosen as the population size for this research. Thus, from the total population, 367 had been selected as a sample size for this study based on the suggestion by Sekaran and Bougie (2016) that mentioned this amount of sampling is appropriate for less than 10,000.

Surprisingly, after the end of the time provided (around two weeks) to collect the responses, this study succeeds in collecting 397 responses, exceed the early target, which is 367 responses. To ensure all the valuable data are optimally utilized, after the screening process for data validation is done, this study decided to use all the collected responses due to the data received are reliable to be analyzed.

\section{Questionnaire design and measurement}

The questionnaire of this study was divided into four sections (Section A, B, C, and D) that consisted of 20 questions. Section A has four questions that contain questions about gender, respondent age, ethnicity, and current academic period linked to demographic profile measurements. Section B consist of five questions was related to the impact on the emotional aspect. In contrast, in Section C, another six questions are related to the effect on the financial aspect that has been asked. Section D contains five elements regarding the questions on dependent variables. The components of the questionnaire are summarised in Table 2.

Table 2. The summary of all items in the questionnaire.

\begin{tabular}{lcl}
\hline \multicolumn{1}{c}{ Variables } & No. of items & Questions \\
\hline Section A: demographic profile & 4 & Question 1-6 \\
Section B: Emotional aspect & 5 & Question 7-11 \\
Section C: Financial aspect & 6 & Question 12-17 \\
Section D: Impact on students & 5 & Question 18-22 \\
\hline
\end{tabular}

Source: self-constructed

The detailed items of section B, C, and D are as followed:

\section{Emotional items:}

i. COVID-19 has a significant effect on my emotional aspect.

ii. I feel traumatized to be in a public area without wearing any hygienic protection.

iii. I feel worried to shake-hand during and after the COVID-19 outbreak.

iv. I will frequently wash my hands after this COVID-19 pandemic.

v. I will avoid the place that I feel is unclean.

\section{Financial items:}

i. I feel the burden in the financial aspect during the COVID-19 outbreak.

ii. I feel my financial wellbeing has been intruded on during and after COVID-19.

iii. I need to restructure my financial planning during the COVID-19.

iv. I need to ask for financial aid or support during the COVID-19 outbreak.

v. Financial planning during the COVID-19 is important for me.

vi. Financial aid from the government is beneficial in covering my daily expenses. 


\section{Impact on student items:}

i. COVID-19 has an impact on the emotional aspect of my daily life.

ii. COVID-19 has an impact on my learning process in the university.

iii. COVID-19 changes my lifestyle to be extra concerned about the hygiene aspect.

iv. COVID-19 intrudes upon my financial planning.

v. COVID-19 changes my daily life, including the way of thinking.

The score range for this scale that is used in this study is shown in Table 3.

Table 3. Measurement scale that is used in this study.

\begin{tabular}{cc}
\hline Scale & Score \\
\hline Totally disagree & 1 \\
Disagree & 2 \\
Neutral & 3 \\
Agree & 4 \\
Agree & 5 \\
\hline
\end{tabular}

Source: Adopted from Preedy and Watson (2010)

\section{Data collection method}

Due to the pandemic, the lockdown, and closing universities factors, this study used an online method to distribute the survey form to the targeted respondents. Thus, this study used the Google Forms approach to spread the questionnaires to the student. To ensure that each respondent can only answer the question once, the system is set to generate each email address that has been used to answer the questionnaire. Through this approach, the system will block the email address that has already been used.

In the context of equal distribution to all levels of education, this study provides the official link to each faculty or department head. Thus he or she will act as a person in charge of distributing the questionnaires to all the under their supervision. This method is used to ensure that all the respondents will get an equal chance to answer the questionnaires. The author provides two weeks as the time frame for the students to answer the questionnaire.

Also important to note, all the respondents involved in this survey have been informed of the objectives and procedures of this study at the beginning of the online questionnaire, and it was conducted according to a guide by Creswell (2005). The confidentiality and anonymity of their data were guaranteed, and they were asked to read the instructions and respond to the scales. Participation in the study was voluntary.

\section{Data analysis strategy}

The following statistical techniques and methods were used to analyze the data and conduct hypothesis testing using the SPSS software:

Reliability test. The accuracy and stability of the data in the survey analysis were determined using reliability. Table 4 displays the results, which were represented using the value of Cronbach's alpha from the pilot and actual tests. Based on Hair et al. (2009) interpretations, the alpha coefficient of more than 0.9 indicates exceptional strength, while a value range of 0.7 to 0.8 indicates a strong interaction between the instruments. 
In this research, a total of forty-five students from the UiTM, Kedah's branch, were chosen to participate in the pilot test before the final questionnaire was distributed. The pilot test aims to ensure that the questions that were asked to respondents are straightforward and to identify any other potential flaws in the question's structure. The researchers conducted the reliability test for each independent and dependent variable in this study. On average, the reliability test has shown that the Cronbach alpha for all variables is considered good. Table 4 shows the result generated via the Cronbach's Alpha value that has been interpreted from the pilot and accurate test. The outcome value was in the range of 0.760 to 0.917 for the pilot and $0.716-0.882$ for the actual test. As a result, all the questions were accepted due to the higher than $0.70(\mathrm{a}>0.7)$ and were accepted to be tested.

Table 4. Result of the Reliability Test (Cronbach's Alpha Value)

\begin{tabular}{lccc}
\hline Variables & No. items & Pilot test & Real test \\
\hline Emotional & 5 & 0.760 & 0.716 \\
Financial & 6 & 0.917 & 0.882 \\
Impact on students & 5 & 0.812 & 0.804 \\
\hline
\end{tabular}

Source: Self-constructed

Descriptive statistic. Descriptive analysis is used to explain the data collected from the respondents and summarize and describe those data. As for the demographic profile, the study used frequency to analyze the respondents' profiles, such as gender, marital status, and others.

Pearson Correlation Analysis. This statistical technique measures the linear association between two potential variables (Hair et al., 2009). Generally, it is used to examine whether there is a relationship between variables and measure the relationship's strength. This research has been applied to identify the relationship between the emotional aspect, financial aspect, and the impact of COVID-19 pandemic among students in higher learning educations in Malaysia.

Multiple Regression Analysis. Most researchers usually use this technique in analyzing data that involve several independent variables with one dependent variable (Gliner et al., 2009). Moreover, this analysis also helps the researchers expand their understanding of how much variance was affected by the dependent variable. Thus, this research used multiple regressions to determine which factors (financial or emotional aspects) had more influence on the impact of COVID-19 among the students in higher education institutions.

\section{Results}

\section{Respondent's demographic profile}

In this analysis, the frequency distribution was used to determine the characteristics of the respondent profile. Relate to the current research, the data were generated from 397 respondents among UiTM Kedah's Branch students. Four questions have been asked on demographic information; these are gender, age, ethnicity, and current academic study.

Table 5. Demographics' result

\begin{tabular}{llcc}
\multicolumn{1}{r}{ Demographic } & \multicolumn{1}{c}{ Items } & No. of Respondents & Percentage (\%) \\
\hline Gander & Male & 74 & 18.6 \\
& Female & 323 & 81.4 \\
Age & $18-22$ & 370 & 93.2 \\
\multirow{2}{*}{ Ethnic } & $23-28$ & 27 & 6.8 \\
& Malay & 396 & 99.7 \\
& Kadazan & 1 & 0.3 \\
\hline
\end{tabular}




\begin{tabular}{llcc}
\hline Current Academic study & Foundation & 8 & 2.0 \\
& Diploma & 232 & 58.4 \\
& Bachelor degree & 157 & 39.5 \\
\hline
\end{tabular}

Source: self-constructed

Based on table 5, with 323 female respondents (81.4\%), most of the respondents in the survey were female, while 74 male respondents made up the remaining 18.6 percent. Regarding the age groups, only 27 respondents $(6.8 \%)$ were between the ages of 23 and 28 years old, while most of the respondents were between the ages of 18 and 22 years old (370 respondents or 93.2 percent). For ethnicity, only one of the respondents $(0.3 \%)$ is Kadazan, and the rest are Malay- representing 396 or $99.7 \%$. Finally, for academic study, most of them are currently in the diploma level (232 respondents or 58.4\%), followed by bachelor degree (157 respondents or $39.5 \%$ ), and the remaining is in the foundation level (8 respondents or $2 \%$ ).

Normally, a correlation coefficient is used to assess the strength of the relationship between two or more variables. The value -1 indicates the perfect negative relationship. The value of 0 indicates no relationship. In contrast, the value of 1 represents a perfect positive relationship (Pallant, 2013). In detail, Cohen (1988) suggested the following principles interpret the correlation's values. First, if the value of correlation is in the range of 0.10 to 0.29 , it indicates a small association between the two variables. For a correlation between 0.30 to 0.49 , the relationship is medium, and it is a strong relationship between two variables when the correlation value is in the range of 0.50 to 1.0 . Meanwhile, the double star $\left.{ }^{* *}\right)$ indicates that a significant relationship exists at a confidence level of 99 percent, with a substantial value of 0.05 .

Table 6 shows the result of bivariate Pearson's correlation between independent variables and the impacts as the dependent variable. Thus, based on the generated data, there are significant positive correlations between independent variables with the dependent variable, which indicated that if an independent variable increases, the dependent variable will also increase. The strength of correlations ranges from $r=.556$ to $r=.565$, where the highest correlation is the financial aspect which indicates that the (r) value is $0.565^{* *}$, and the emotional element represents .556. Thus, both the independent variables have a strong relationship towards students' impact during the COVID-19 pandemic due to the value of $r$, which is more than 0.5 . Therefore, hypothesis 1 of this research is accepted.

Table 6. Correlation between the impact of COVID-19 among students in higher learning institutions towards financial and emotional aspects of student

\begin{tabular}{ll}
\hline Variables & Impact towards students \\
\hline Financial aspect & $.565^{* *}$ \\
Emotional aspect & $.556^{* *}$ \\
\hline
\end{tabular}

** Correlation is significant at the 0.05 level (2-tailed).

Source: self-constructed

Multiple regression analysis was used to determine the effect of emotional and financial factors towards COVID-19 among Malaysian students in higher education institutions. Thus, the result revealed that the $\mathrm{R}^{2}$ value was 0.471 or $47.1 \%$. The current study represents $47.1 \%$ of the variance in the effect of COVID-19 among the students was significantly influenced by the two independent variables in this survey, i.e., the emotional and financial aspects. On the other hand, the remaining 53\% of the element was determined by other factors.

Besides, the unstandardized $\beta$-coefficient for the emotional aspect had a significant value of 0.448 , whereas the financial aspect was only 0.279 . Therefore, it is clear that both of the variables significantly influence the impacts of students due to the value are more than 0.05. Thus, hypothesis 2 in this study is accepted. 
Table 7. Regression analysis between financial and emotional aspects towards dependent variable

\begin{tabular}{lcccrc} 
& \multicolumn{2}{c}{$\begin{array}{c}\text { Unstandardized } \\
\text { Coefficients }\end{array}$} & $\begin{array}{c}\text { Standardized } \\
\text { Coefficients }\end{array}$ & t & Sig. \\
\cline { 2 - 4 } & $\mathrm{B}$ & Std. Error & Beta & & \\
(Constant) & 5.394 & .890 & & 6.063 & .000 \\
Financial Aspect & .279 & .026 & .427 & 10.856 & .000 \\
Emotional Aspect & .448 & .043 & .413 & 10.516 & .000
\end{tabular}

Dependent Variable: Impact on Students

$\mathrm{R}^{2}=0.471, \mathrm{~F}-$ Value $=171.865$

Source: self-constructed

\section{Discussion}

The demographics background of respondents is one of the important aspects that need to be adequately analyzed; this is because the different backgrounds of the respondents will indicate the other need and approach. This is in line with several studies such as Singh (2014), Wahab (2018), Naim et al. (2019), and Wahab and Tajuddin (2019) that have stated that demographic factors play an important role to improve and overcome specific issues. Based on the study, the respondent's background is from the students' perspectives from higher learning institutions. For example, the difference in the age of the students might be the result due to the difference in technology literacy. The older students might be much better in technology literacy compared to the younger students. Thus, the approach of the university management must also differentiate based on the students' age to suit and match their current satisfaction and needs.

The educational level analysis also plays an essential role in demographic profile. This is parallel with previous researches, such as by Tsai et al. (2013), Jayawardhena et al. (2009), Munnukka (2007), and Porter and Donthu (2006) that have mentioned that a person's knowledge and educational background enables him or her to change his or her decision-making. In the scope of this study, the different levels of educational study play significant differences in the context of their respective need. For example, while the finance students at the foundation level might need the basic financial calculator to solve the questions in their study, the finance students at the bachelor degree level might need the scientific, financial calculator in their study.

Moreover, the different background of study will also result in the difference in needs and wants. For instance, the art and science students might need more lab equipment and tools than the social science students who might need more gadgets and internet infrastructure to complete their study. Those elements are needed to differentiate the lecturers' and universities' approaches to overcome the students' issues. Therefore, it is proven that the analysis of the demographic factors plays a vital role in managing the students' issues.

This study has provided valuable results for the universities to formulate a practical approach to mitigate the financial and emotional issues among their students since both variables significantly influence student's impact. First, the universities cannot ignore the fact that the financial and emotional aspects significantly influence the students in higher education institutions during the COVID-19 outbreak. Second, universities' approaches and programs must be appropriate for students' interests depending on their demographics background characteristics. Thirdly, this study also identified that the students come from different educational levels such as foundation, diploma, or bachelor's degree. Hence, the universities should consider such factors in their decision-making; otherwise, the welfare of the students will not be achieved.

Based on the current literature, many studies were carried out on the impact of COVID-19 among students on the various scope, such as by Shehzadi et al. (2020), Nguyen et al. (2020), Sheela Sundarasen et al. (2020), and others. However, there is a lack of researchers investigating the aspects of students' financial and emotional 
impact during the COVID-19's transmission. In terms of the result findings, this paper is consistent with the above-stated studies showing that students' financial and emotional aspects will be interrupted when certain problems occur during their study period.

Due to the seemingly endless nature of the pandemic up to date, the universities should frequently conduct a survey to assess the possible factors that cause problems to their students; this study shows empirical evidence in determining their impacts. The issues and needs of the students continuously change over time based on their current experiences. Thus, further studies should be done regularly to keep up with the students' satisfaction regarding the effects of the COVID-19 pandemic.

\section{Conclusion}

The first objective that aimed to be answered is to determine whether there was a significant relationship between the emotional aspect, financial aspect, and the impact of COVID-19 among students in Malaysian higher education institutions. The results illustrate a significant positive relationship between all the factors tested (financial aspect and emotional aspect) where the strength ranges from $r=.556$ to $r=.565$. It is important to highlight that the highest correlation is the financial aspect (r-value .565) and is followed by the emotional element that represents .556. Thus, both of the independent variables have a strong relationship towards students' impact during the COVID-19 pandemic due to the value of $\mathrm{r}$ that is more than 0.5 .

Next, the second objective was to identify the significant influence between the emotional, financial, and impact of COVID-19 among students in the higher learning institutions in Malaysia. The results revealed that both variables were significantly influenced where the $\mathrm{R}^{2}$ value was 0.471 or $47.1 \%$. In other words, both variables indicated a $47.1 \%$ influence towards the impact of a dependant variable while other untested factors explained the additional $53 \%$ of the variance.

\section{Practical implications}

Generally, this paper proves that students in higher education institutions are affected by the COVID-19 from internal and external factors. Thus, the findings of this research have a host of practical consequences for specific classes. First, concerning students, this study is helpful to them to develop contingency plans to overcome the issue of financial and emotional problems that they might be faced with during the pandemic. For example, they can adjust their current financial expenditure to suit the current situation. They should reduce unnecessary expenses and try to manage their scholarship correctly. One of the effective ways to properly manage their finance is through developing their financial statement that states all the sources of income and expenses.

In mitigating the emotional issue, they can apply several approaches such as identifying the main issues that are to be faced, creating a good environment, changing mindset, rescheduling the learning timetable, taking enough rest, etc. The adoption of these approaches can be varied for each student and is based on the main issues they face. For example, demotivated students might need to change their mindset to become more positive to adopt new learning approaches. In any situation, the critical point is that the students should always consider and monitor their emotional aspect to ensure that their learning process can be fun and progress smoothly.

Second, concerning the higher learning institutions, this research can help them formulate strategies to minimize the impact of COVID-19 among their students. For example, universities would apply many steps and precautions to mitigate the transmission of the virus among their students and staff. The university management should be responsible for developing comprehensive methods and a road map to control the pandemic in their universities. Besides, universities should also regularly update the current information of the pandemic that is useful to their staff and students; archiving health and safety is the top priority among staff and students, and adequate counseling facilities should be provided to help their mental health and wellbeing. 
For students who stay on the campus, the university management should ensure that their welfare is in good condition at all times. For example, university management should ensure that food and accommodation for the international students are well serviced. In online learning, the universities should ensure that the internet and technology infrastructure in the campus is good to create better student experiences in adopting the new ways of learning method, i.e., through online and self-learning.

\section{Theoretical implications}

In the academician's context, this study can help in enriching the current literature that is namely related to the COVID-19 pandemic, which is still limited. The findings from this research are useful to the academicians to expand the study by adding other possible factors related to the pandemic's impact. Besides, the questionnaires from this study can also guide them in adopting another research about the COVID-19.

\section{Limitations}

This research has identified certain limitations. First, since this study only looked at one university out of 20 public higher learning institutions in Malaysia, it can be concluded that the location and target respondents were limited. Second, the current study's sample size is considered small as the focus is on 397 respondents only compared to the number of students in public higher learning institutions in Malaysia. Hence, it is suggested that future studies be expanded to include other public higher learning institutions and increase the sample size of the respondents to collect a diverse set of data and answers. Next, as is known, the present study only focusses on two variables, i.e., the financial and emotional aspects of the students due to the impact of the COVID-19. Therefore, other possible variables would be included to know other factors that might be the impact from the pandemic for further study.

Funding: This research received no external funding.

Acknowledgments: I acknowledge the Faculty Business and Management, Universiti Teknologi Mara Malaysia (UiTM), Kedah's branch, by permitting to conduct the research.

Conflicts of Interest: The author declares no conflict of interest.

\section{References}

Al-Rabiaah, A., Temsah, M. H., Al-Eyadhy, A. A., Hasan, G. M., Al-Zamil, F., Al-Subaie, S., ... \& Somily, A. M. (2020). Middle East Respiratory Syndrome-Corona Virus (MERS-CoV) associated stress among medical students at a university teaching hospital in Saudi Arabia. Journal of Infection and Public Health, 13(5), 687-691. https://doi.org/10.1016/j.jiph.2020.01.005

Aristovnik, A.; Keržič, D.; Ravšelj, D.; Tomaževič, N.; Umek, L. (2020). Impacts of the COVID-19 Pandemic on Life of Higher Education Students: A Global Perspective, Sustainability, 12(8438), 1-34.

Bodvarsson, O.B., \& Walker, R.L. (2004). Do parental cash transfers weaken performance in college?, Economics of Education Review, 23(5), 483-495.

Brooks, S.K.; Webster, R.K.; Smith, L.E.; Woodland, L.; Wessely, S.; Greenberg, N.; Rubin, G.J. (2020). The psychological impact of quarantine and how to reduce it: Rapid review of the evidence, Lancet, 395, 912-920.

Cao, W.; Fang, Z.; Hou, G.; Han, M.; Xu, X.; Dong, J.; Zheng, (2020). The psychological impact of the COVID-19 epidemic on college students in China. J. Psychiatry Res., 287:112934. doi: 10.1016/j.psychres.2020.112934.

Cohen, J. (1988). Statistical power analysis for the behavioral science (2nd edition). Hillsdale, NJ: Lawrence Erlbaum.

Creswell, J. W. (2005). Educational research: Planning, conducting, and evaluating quantitative and qualitative research. Upper Saddle River, New Jersey: Pearson Education, Inc. 
Crispim, J. S.; Vaz, M. G. M. V.; Pereira, K. F.; da Silva, J. D.; da Silva Duarte, V.; Sanches, N. M.; Mantovani, H. C.; Dos Santos, M. T.; Peluzio, L. E.; Dos Santos, J. K.; de Paula, S. O. (2021). Teaching learning: a mutual exchange between high school and graduate students in the field of microbiology, FEMS Microbiology Letters, 368(1). https://doi.org/10.1093/femsle/fnaa199

Edirisuriya, P. (2015). The Predictive Power of Financial Variables: New Evidence from Australia, Australasian Accounting, Business and Finance Journal, 9(1), 57-70. doi:10.14453/aabfj.v9i1.5

Elmer, T.; Mepham, K.; Stadtfeld, C. (2020). Students under lockdown: Comparisons of students' social networks and mental health before and during the COVID-19 crisis in Switzerland. PLoS ONE, $15,1-22$.

Faulk, D.; Srinivasan, A.; Bingham, J. (2010). Sources of Financial Support and Academic Performance in Economics Principles Courses, SSRN Electronic Journal, pp. 1-33. DOI: 10.2139/ssrn.1711172.

Gewin, V. (2020). Five tips for moving teaching online as COVID-19 takes hold, Nature, 580(7802), 295-296. doi:10.1038/d41586-020-00896-7

Gläser-Zikuda, M., Fuß, S., Laukenmann, M., Metz, K. and Randler, C. (2005). Promoting Students' Emotions and Achievement - Conception and Evaluation of the ECOLE Approach. Learning and Instruction, $15,481-495$.

Gliner, J. A., Morgan, G. A. \& Leech, N. L. (2009). Research method in applied settings: An integrated approach to design and analysis. New York, NY: Taylor \& Francis.

Grubic, N.; Badovinac, S.; Johri, A.M. (2020) Student mental health in the midst of the COVID-19 pandemic: A call for further research and immediate solutions. Int. J. Soc. Psychiatry, 66, 517-518.

Gutiérrez, T. (2020). How to Pay for Your Studies during the Coronavirus Outbreak. Retrieved from https://www.mastersportal.com/articles/2791/how-to-pay-for-your-studies-during-the-coronavirusoutbreak.html on 12 December 2020.

Hair, J.F., Jr, Black, W.C., Babin, B.J. and Anderson, R.E. (2009), Multivariate Data Analysis, 7th Ed., Prentice Hall, Upper Saddle River, NJ.

Irfan, M.; Shabana, N. K. (2012). Factors Affecting Students' Academic Performance, Global Journal of Management and Business Research, 12(9), 17-22. Online ISSN: 2249-4588 \& Print ISSN: 0975-5853.

Jayawardhena, C.; Kuckertz, A.; Karjaluoto, H.; Kautonen, T. (2009). Antecedents to permission based mobile marketing: An initial examination. European Journal of Marketing, 43(3/4), 473-499.

Kafka. A. (2020). Shock, fear, and fatalism: as coronavirus prompts colleges to close, students grapple with uncertainty. Accessed: July 19, 2020: https://www.chronicle.com/article/Shock-FearFatalismAs $/ 248240$.

Kawano, S.; Kakehashi, M. (2015). Substantial impact of school closure on the transmission dynamics during the pandemic flu H1N1-2009 in Oita, Japan, PLoS One, 10(12), 1-15. https://doi.org/10.1371/journal.pone.0144839.

Laukenmann, M., Bleicher, M., Fuß, S., Gläser-Zikuda, M., Mayring, P. and Rhöneck, C. (2003). An Investigation on the Influence of Emotions on Learning in Physics. International Journal of Science Education $25,489-507$.

Lyons, A. C. (2004). A Profile of Financially At-Risk College Students. The Journal of Consumer Affairs, 38, 56-80.

Lyons, A.C. (2003). Credit Practices and Financial Education Needs of Midwest College Students. Champaign, ILll, Department of Agricultural and Consumer Economics, University of Illinois at Urbana-Champaign.

Munnukka, J. (2007). Characteristics of early adopters in mobile communications markets. Marketing Intelligence \& Planning, 25(7), 719-731.

Naim, A. M.; Abd. Hamid, M. L.; Haji Wahab, M. Z. (2019). The Roles of Lifestyle, Future Need and Customer Preferences in Customer's Satisfaction on Islamic Banks Products and Services. Journal of Muamalat and Islamic Finance Research, 16(2), 60-76. DOI: https://doi.org/10.33102/jmifr.v16i2.223. 
Nguyen, D. V; Pham G. H; Nguyen D.N., (2020). Impact of the Covid-19 pandemic on perceptions and behaviors of university students in Vietnam, Data in Brief, 31, 1-6. https://doi.org/10.1016/j.dib.2020.105880

Nnamani, C. N.; Dikko, H. G.; Kinta, L. M (2014). Impact of Students' Financial Strength on their Academic Performance: Kaduna Polytechnic Experience. An International Multidisciplinary Journal, 8 (1), Serial No. 32, 83-98. DOI: http://dx.doi.org/10.4314/afrrev.v8i1.7.

OECD (2020). A framework to guide an educational response to the COVID-19 Pandemic of 2020, Retrieved from https://read.oecd-ilibrary.org/view/?ref=126_126988-t631xosohs\&title=A framework-to-guide-an-educationresponse-to-the-Covid-19-Pandemic-of-2020, p. 7.

Pallant, J. (2013). SPSS survival manual. A step by step guide to data analysis using IBM SPSS. United Kingdom, UK: McGraw-Hill Education.

Pekrun, R.; Götz, T.; Titz, W.; Perry, R. P. (2002). Academic Emotions in Students' Self Regulated Learning and Achievement: A program of qualitative and quantitative research. Educational Psychologist, 37, 91-105.

Pintrich, P. R.; Marx, R. W.; Boyle, R. A. (1993). Beyond Cold Conceptual Change. The Role of Motivational Beliefs and Classroom Contextual Factors in the Process of Conceptual Change. Review of Educational Research, 63, 167-199.

Porter, C. E.; Donthu, N. (2006). Using the technology acceptance model to explain how attitudes determine internet usage: The role of perceived access barriers and demographics. Journal of Business Research, 59(9), 999-1007.

Pradeep, S. (2020). Closure of Universities Due to Coronavirus Disease 2019 (COVID-19): Impact on Education and Mental Health of Students and Academic Staff, Cureus article, $\quad 12(4)$ : e7541. DOI 10.7759 /cureus.7541.

Preedy V.R.; Watson R.R. (2010). 5-Point Likert Scale. In (eds) Handbook of Disease Burdens and Quality of Life Measures. Springer, New York, NY. https://doi.org/10.1007/978-0-387-78665-0_6363.

Reynolds, M. (2020). What is coronavirus and how close is it to becoming a pandemic?. (Accessed date 27, December 2020). Available online at / /www.wired.co.uk/article/china-coronavirus.

Sekaran, U.; Bougie, R. (2016). Research methods for business: a skill-building approach (7th ed.). Haddington: John Wiley \& Sons.

Sundarasen, S.; Chinna, K.; Kamaludin, K.; Nurunnabi, M.; Baloch, G. M.; Khoshaim, H.B.; Abid Hossain, S. F.; Sukayt, A. (2020). Psychological Impact of COVID-19 and Lockdown among University Students in Malaysia: Implications and Policy Recommendations, Int. J. Environ. Res. Public Health, 17(6206), 1-13. doi:10.3390/ijerph17176206.

Shehzadi, S.; Nisar, Q.A.; Hussain, M.S.; Basheer, M.F.; Hameed, W.U.; Chaudhry, N.I. (2020). The role of digital learning toward students' satisfaction and university brand image at educational institutes of Pakistan: a post-effect of COVID-19, Asian Education and Development Studies, 10(2), 276-294. https://doi.org/10.1108/AEDS-04-2020-0063.

Singh, S. (2014). Customer perception of mobile banking: An empirical study in National Capital Region Delhi. Journal of Internet Banking and Commerce, 19(3), 2-23.

Statista (2020). Impact of the COVID-19 Pandemic on Work and Studies in Singapore as of March 2020. Retrieved from https://www.statista.com/statistics/1112253/singapore-impact-on-jobs-and-studies-duringcovid-19/.

Selye H. (1976). Stress in health and disease, Butterworth's, Inc.Boston, MA:

THE. (2020a). The COVID-19 crisis and international students. Retrieved from https://www.insidehighered.com/views/2020/03/19/higher-ed-institutions-arent-supportinginternational-students-enough on July 19, 2020.

THE. (2020b). Educating despite the COVID-19 outbreak: lessons from Singapore. Retrieved from https://www.timeshighereducation.com/blog/educating-despite-Covid-19-outbreak-lessons-

Singapore on March 20, 2020. 
THE. (2020c). Will the coronavirus make online education go viral?. Retrieved from https://www.timeshighereducation.com/features/will-coronavirus-make-online-educationgo-viral on March 24, 2020.

Tsai, C.; Zhu, D.; Jang, Y. (2013). A study on the consumer adoption behaviors of internet bank. Journal of Networks, 8(12), 2956-2963.

UNESCO. (2020). COVID-19 Educational Disruption and Response. Retrieved from https://en.unesco.org/Covid19/educationresponse.

Wahab, M. Z. (2018). Perception of the Takaful Operators' Performance towards Customer's Intention in Using Medical Takaful Card among Public Sector. Journal of Islamic Marketing, 9(3), 527543. DOI: https://doi.org/10.1108/JIMA-10-2016-0076.

Wahab, M. Z.; Tajuddin, A. M. (2019). The Roles of Health Awareness and Knowledge in Medical Takaful Purchase Intention, The International Journal of Banking and Finance, 14, 95-116.

Wang, G.; Zhang, Y.; Zhao, J.; Zhang, J.; Jiang, F. (2020) Mitigate the effects of home confinement on children during the COVID-19 outbreak. Lancet, 395, 945-947.

Wheeler, C.C.; Erhart, L. M.; Jehn, M. L. (2010). Effect of school closure on the incidence of influenza among school age children in Arizona. Public Health Rep., 125:851859. 10.1177/003335491012500612

World Health Organization (2020, March 23). WHO announces COVID-19 outbreak a pandemic. Retrieved from http://www.euro.who.int/en/health-topics/health-emergencies/coronavirus-Covid19/news/news/2020/3/who-announces-Covid-19outbreak-a-pandemic.

World Health Organization (2021, May 3). WHO Coronavirus (COVID-19) Dashboard, Retrieved from https://covid19.who.int/on 3 May 2021. 